\title{
Reversal of transforming growth factor- $\beta$ induced epithelial-to-mesenchymal transition and the ZEB proteins
}

\author{
Shreyasi Das ${ }^{1 *}$, Bryan N Becker ${ }^{2}$, F Michael Hoffmann $^{3,4}$, Janet E Mertz ${ }^{4}$ \\ From Fibroproliferative disorders: from biochemical analysis to targeted therapies \\ Frauenchiemsee, Germany. 25-30 September 2010
}

\begin{abstract}
Background: The dynamic process of epithelial-to-mesenchymal transition (EMT) is a causal event in kidney fibrosis. This cellular phenotypic transition involves activation of transcriptional responses and remodeling of cellular structures to change cellular function. The molecular mechanisms that directly contribute to the re-establishment of the epithelial phenotype are poorly understood.

Results: Here, we discuss recent studies from our group and other laboratories identifying signaling pathways leading to the reversal of EMT in fibrotic models. We also present evidence that transcriptional factors such as the ZEB proteins are important regulators for reversal of EMT.
\end{abstract}

Conclusion: These studies provide insights into cellular plasticity and possible targets for therapeutic intervention.

\section{Background}

Kidney failure is a serious medical problem with limited therapeutic choices available. The kidney is a vital organ in the body as it regulates blood pressure, volume, $\mathrm{pH}$, and levels of electrolytes and metabolites [1]. Proximal tubule epithelial cells are one of the key components of the kidney as they carry out the cellular functions necessary for filtering the blood. Epithelial cells can loose filtering functions during injury to the kidney when exposed to cytokines such as transforming growth factor $\beta$ (TGF- $\beta$ ) [2]. In many cases, injury to the kidney is temporary, with epithelial cells able to regenerate. However, when diseases such as diabetes, hypertension, and polycystic kidney disease are poorly controlled, chronic injury to the proximal tubule epithelial cells, and eventually, kidney failure can occur. Unfortunately, doctors and patients can only manage the medical problems that present themselves following kidney damage since there are no treatments currently available to regain kidney function. Thus, understanding

\footnotetext{
* Correspondence: sdas@sanfordburnham.org

'Sanford-Burnham Medical Research Institute, 10901 N. Torrey Pines Road, La Jolla, CA 92037, USA

Full list of author information is available at the end of the article
}

the molecular mechanisms leading to kidney disease and developing specific therapies is of great importance.

\section{Basics of epithelial-to-mesenchymal transition as a biological process}

Epithelial-to-mesenchymal transition (EMT) is the major causative event of kidney cells loosing function during injury of the kidney and chronic kidney disease $[3,4]$. The principle behind EMT is polarized epithelial cells in well organized layers convert to individual, motile fibroblasts [4-7]. The transition is characterized by the loss of epithelial morphology, reduction of cell-cell contacts, transcriptional repression of E-cadherin expression, degradation of cell-matrix adhesions, and rearrangement of the actin cytoskeleton. The mesenchymal fibroblasts in culture appear as long, spindle-shaped cells, capable of migration and possessing the ability to produce extracellular matrix. The changes that occur during the course of EMT do not only affect the cell itself, but also the environment surrounding the cell [8-10]. This process is reversible in normal processes such as gastrulation and organogenesis of the heart, musculoskeletal system, and the peripheral nervous system as well as in diseased 
states such as primary tumor metastasis $[3,6]$. Thus, one way to regain kidney function would be to find therapeutic agents that can reverse EMT.

\section{Transforming growth factor- $\beta$ is an essential inducer of EMT}

When basement membranes are damaged, the attached epithelial cells secrete cytokines to initiate EMT $[3,8,10]$. Growth factors such as transforming growth factor- $\beta$ (TGF- $\beta$ ) are required to induce and maintain EMT; they do so via both Smad-dependent and -independent signaling events [7-15]. Several in vivo and in vitro models of fibrosis exhibit increased TGF- $\beta 1$ expression in damaged tissues $[3,6,10]$. The cellular signaling commences by TGF- $\beta$ ligand binding to a heteromeric complex of transmembrane serine/threonine kinases, type I and type II receptors (T $\beta R I$ and T $\beta R I I)$ [15]. T $\beta$ RII transphosphorylates T $\beta R I$, activating its kinase function. Functioning as a docking site, T $\beta R I$ then directly phosphorylates Smad2 and Smad3 at carboxy-terminal serines [16,17]. Phosphorylated Smad2/3 associates with Smad4 in the cytoplasm. This complex is then translocated to the nucleus where it accumulates [17]. The Smad complex sequencespecifically binds to sites in the DNA, interacting with transcriptional coactivators or corepressors to regulate gene expression. Numerous studies have demonstrated that the TGF- $\beta$ target genes regulating EMT are controlled through Smad signaling $[7,13,14]$. Over-expression of Smad 2 or Smad3 leads to an increase in EMT in mammary epithelial cells. Smad3 knockout mice exhibit amelioration of epithelial degeneration as demonstrated in a lens injury model. SB431542, a potent inhibitor of TGF- $\beta$ Receptor Type I (T $\beta$ RI) kinase activity blocks TGF- $\beta$-induced EMT in Namru Murine Mammary gland (NMuMG) cells $[18,19]$. Over-expression of mutant TR $\beta$ I that lacks the ability to bind to Smad2/3 inhibits TGF- $\beta$ induced EMT in NMuMg cells [20]. Over-expression of inhibitory Smad7 blocks fibrosis in renal UUO models and EMT in retinal epithelium in vitro [21]. Lastly, Zavadil and colleagues demonstrated that TGF- $\beta$ fails to fully induce EMT morphology and to stimulate key transcriptional regulators in primary murine proximal tubules cells isolated from Smad3 knockout kidneys [22].

\section{Macromolecules may be useful to understand which pathways are important for EMT reversal}

In renal fibrosis, tubular epithelial cells undergo EMT in response to insults generated by diseases such as diabetes or hypertension $[23,24]$. The converted fibroblasts produce excessive extracellular matrix, eventually resulting in end-state organ failure where there is currently no method of curing available [8]. Most studies concentrate only on blocking EMT; rarely has a study actually reversed EMT.
Bone morphogenic protein-7 (BMP-7) is a member of the TGF- $\beta$ superfamily $[15,25,26]$. Its recombinant protein ligands are in clinical trials as therapeutics for healing bone fractures [27]. Currently, BMP-7 is the most successful pre-clinical candidate to reverse EMT $[2,24,28]$. TGF$\beta 1$-induced EMT was reversed by treatment for 48 hours with 100 pM BMP-7 as observed by re-establishment of E-cadherin at cell junctions. BMP-7 can reverse fibrosis in an adult kidney. BMP-7 was administered in a chronic injury mouse model and produced amelioration of kidney fibrosis after one week. The EMT reversal was accomplished by BMP-7 antagonizing the TGF- $\beta$ pathway and activating the epithelial transcriptional programming through Smads 1, 5, and 7 [28,29]. However, it remains to be elucidated which epithelial and mesenchymal genes are regulated by BMP-7.

Hepatocyte growth factor (HGF) is another macromolecule that has been studied for its ability to reverse EMT by antagonizing the TGF- $\beta$ pathway, doing so through induction of expression of the Smad-binding inhibitory protein SnoN [30]. Administration of HGF partially reverses TGF- $\beta$-induced EMT in mouse kidney cells $[31,32]$. Unlike BMP-7, which is a potent reversal agent of EMT, HGF fails to completely reverse EMT in an in vivo UUO mouse model; a fibrotic marker is still observed in the cells [33]. This finding can be explained by HGF acting as an inducer of an EMT-like phenotype termed reversible scatter, suggesting that HGF has dual functions during cellular differentiation [34].

\section{Results and discussion}

Small molecules targeting cellular signaling protein intermediates both elucidate major EMT signaling events and can be developed as agents to reverse EMT

The studies using macromolecules such as BMP and HGF elucidated major signaling pathways important for EMT reversal. However, specific signaling pathway intermediates and transcription factors that maintain the mesenchymal program were still unknown. To identify factors that maintain the mesenchymal state, our group tested five different kinase inhibitors targeting T $\beta R I$, p38 mitogen-activated protein kinase (p38 MAPK), MAP kinase kinase/ extracellular signal-regulated kinase activator kinase (MEK1), c-Jun NH-terminal kinase (JNK), and Rho kinase (ROCK) with SB431542, SB203580, U0126, SP600125, and Y27632, respectively, for their ability to reverse EMT induced by TGF- $\beta 1$ in primary renal cells isolated from a TGF- $\beta 1$ knockout mouse (mTEC-KO) [19,35-40]. The mTEC-KO cells were initially exposed to TGF- $\beta 1$ to induce EMT, the kinase inhibitor was added, and the cells were examined for signs of reversal to an epithelial state [40]. Treatment with the single kinase inhibitors listed above did not completely reverse the mesenchymal phenotype as depicted by gene expression and morphological 
changes. Of the five individual inhibitors, only the T $\beta R I$ inhibitor, SB431542, partially ameliorated the EMT phenotype by aiding in the reappearance of epithelial cadherins and decreasing mesenchymal gene expression. These findings suggested that blocking the TGF- $\beta$ signaling pathway during the mesenchymal state only regulates gene expression, but does not induce the structural changes required to re-establish the epithelial phenotype.

Since EMT effects are mediated by multiple cellular pathways, a combination of the kinase inhibitors was used to understand if two intracellular signals need to be blocked for EMT reversal to occur. This idea is consistent with a study that reported reversal of a mesenchymal phenotype caused by conditional Fos over-expression in EpH4 through the use of a combination of constitutively active $E$-cadherin and a small molecule inhibitor of TGF- $\beta$, BIBU 3029 [41]. When our TGF- $\beta$-induced mesenchymal cells were incubated for 24 hours with the T $\beta R I$ inhibitor SB431542 in combination with either the p38 MAPK inhibitor SB203580 or the RhoA inhibitor Y27632, the epithelial appearance of the cells was restored as indicated by a reduction in stress fibers and mesenchymal gene expression [40]. Taken together, these findings indicate that TGF- $\beta$ maintains the mesenchymal phenotype through sustained activation of Smad-dependent transcriptional responses and elements downstream of ROCK or p38 MAPK.

The use of small molecule inhibitors of individual protein kinases not only demonstrates their potential for dissecting mechanisms of signal transduction for specific ligands and for delineating their roles in biologic responses, but also their potential as therapeutic agents. However, it remains to be seen which molecules will be useful for EMT reversal in clinical models.

\section{The ZEB protein family is an attractive target as an EMT reversal agent}

The loss of transcriptional repressors from the promoter regions of genes central to the epithelial phenotype is a possible mechanism for the re-expression of these epithelial-specific genes during the reversal of EMT induced by macromolecules or cellular signaling kinase inhibitors. Smad-dependent signaling up-regulates expression of several transcription factors important for EMT induction, including Snail (Snai1), Slug (Snai2), Twist, and members of the ZFH family, ZEB1 (also called EF1, TCF8, AREB6, ZFHEP, NIL-2A, ZFHX1A, and BZP) and ZEB2 (also called SIP1, SMADIP1, ZFHX1B, and KIAA0569), making them good candidates to regulate the reversal of EMT [42-44]. These transcription factors activate EMT by binding to elements present in the promoter regions of a number of epithelial-specific genes including the E-cadherin promoter, thus suppressing synthesis of this cell-cell adhesion protein [7,45-47]. The involvement of the ZEB transcription factors is particularly tantalizing as an EMT reversal target since they regulate gene expression critical for both organ development and cancer metastasis [48]. The loss of ZEB2 in fetal mice results in a number of developmental defects, including the loss of migratory capabilities of neural crest cells [49]. Others have provided evidence for the role of the ZEB proteins during the induction of EMT by their repressing expression of E-cadherin and other epithelial structural components necessary for epithelial phenotype [44,50,51]. Additionally, the microRNA 200 family induces mensenchymal-to-epithelial transition in certain cancer cell lines [52]. Mutations in the TCF8 gene (GenBank accession number NM 030751) result in a mesenchymal-to-epithelial transition (MET) in mouse embryos by reprogramming gene expression, leading to developmental defects by diminishing progenitor cell proliferation and cell migration [53]. In Madin-Darby Canine Kidney (MDCK) cells, EMT is preceded by the loss of mature microRNA200a-c, inducing up-regulation of ZEB1 and ZEB2 expression followed by loss of E-cadherin expression and transition to the mesenchymal state. Taken together, these studies indicate transcriptional factors such as the ZEB proteins may be a more specific target for fibrotic therapeutics than drugs that interfere with signaling pathway intermediates.

Our group also examined the effects of ZEB1 and ZEB2 levels during the reversal of EMT Their expression is regulated by TGF- $\beta$ [13], and they are highly expressed in fetal kidney cells [54]. NMuMG cells, a traditional EMT model [55] where ZEB is highly expressed [44], were incubated with TGF- $\beta 1$ to induce EMT, and then the five kinase inhibitors targeting T $\beta$ RI, p38 MAPK, MEK1, JNK, and ROCK were individually added as a reversal agent [40]. We observed that reversal of EMT by the T $\beta R I$ inhibitor SB431542 involves, in part, inhibiting expression of ZEB1. Further studies demonstrated that depleting mesenchymal cells of ZEB1 and ZEB2 with specific shRNAs was insufficient to restore epithelial-specific protein expression such as E-cadherin [40]. However, targeting ZEB1 and ZEB2 with shRNAs along with adding a ROCK inhibitor led to complete reduction of stress fibers and restoration of epithelial protein expression. Taken together, these data provide evidence that inhibition of the TGF- $\beta$ pathway regulates the transcriptional expression of epithelial-specific genes via the ZEBs, while other factors such as the Rho kinases are essential to re-establish the epithelial cell structure (Figure 1).

In summary, treatment strategies targeting the TGF- $\beta$ signaling pathway are attainable antifibrotic options in kidney disease. Specifically, macromolecules such as BMP-7 and HGF have shown promising results in preclinical studies. Our own studies provide evidence regarding which 


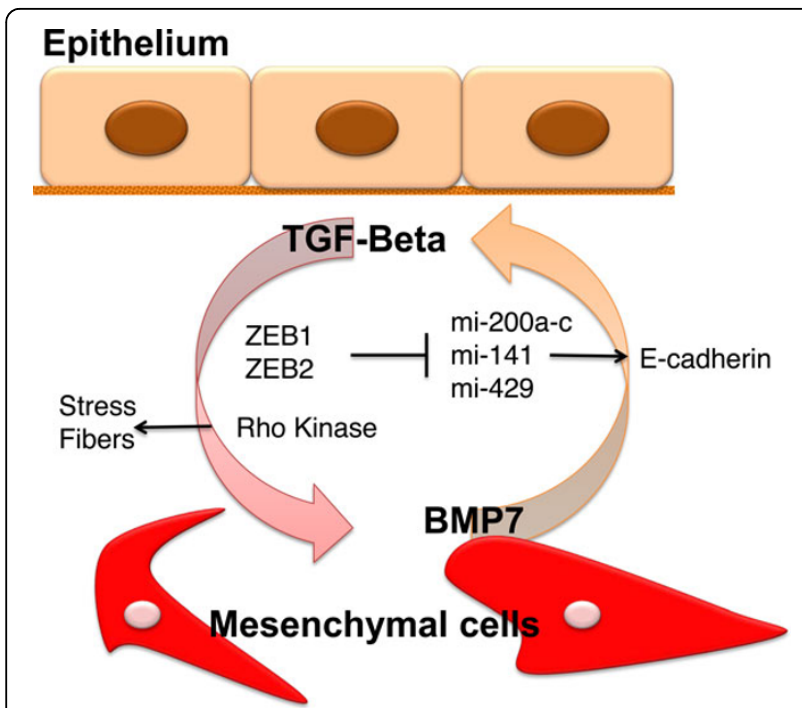

Figure 1 Diagram of key events during EMT and MET. TGF- $\beta$ induces five events for epithelial cells to transition into the mesenchymal state: (i) loss of cell-cell contact, (ii) synthesis of mesenchymal proteins, (iii) re-arrangement of cell structural proteins such as actin, (iv) loss of basement membrane, (iv) loss of apicalbasal polarity, and (v) the reverse, mesenchymal to epithelial transition can be induced by cytokines such as BMP-7.

specific signaling proteins and transcription factors are involved in the EMT reversal process, thus providing potential therapeutic targets.

\section{List of abbreviations used}

EMT: epithelial to mesenchymal transition; JNK: c-Jun NH-terminal kinase; MEK1: MAPK/extracellular signal-regulated kinase; mTEC-KO: murine tubular epithelial cells from TGF- $\beta$ knockout mouse; p38 MAPK: p38 mitogenactivated protein kinase; NMuMG: Namru murine mammary gland; ROCK: Rho kinase; TGF- $\beta$ : Transforming Growth Factor $\beta$; T $\beta$ RI: Transforming Growth Factor- $\beta$ Receptor Type I.

\section{Acknowledgements}

This article has been published as part of Fibrogenesis \& Tissue Repair Volume 5 Supplement 1, 2012: Proceedings of Fibroproliferative disorders: from biochemical analysis to targeted therapies. The full contents of the supplement are available online at http://www.fibrogenesis.com/supplements/5/S1. These studies were supported by US Health and Human Services N.I.H. grants CA090875 to FMH, DK064336 to BNB, and Al071928 and CA022443 to JEM. SD was supported in part by T32-CA09135 from the National Institute of Health.

\section{Author details}

'Sanford-Burnham Medical Research Institute, 10901 N. Torrey Pines Road, La Jolla, CA 92037, USA. ${ }^{2}$ Department of Medicine, University of Wisconsin School of Medicine and Public Health, 600 Highland Avenue, Madison, Wisconsin 53792, USA. ${ }^{3}$ Laboratory of Genetics, University of Wisconsin School of Medicine and Public Health, 425-G Henry Mall, Madison, Wisconsin 53706, USA. ${ }^{4}$ McArdle Laboratory for Cancer Research, University of Wisconsin School of Medicine and Public Health, 1400 University Ave, Madison, Wisconsin 53706, USA.

\section{Authors' contributions}

SD prepared the manuscript. FMH and JEM edited the manuscript. All authors read and approved the final manuscript. BNB, FMH, and JEM provided funding.

\section{Competing interests}

The authors declare that they have no competing interests.

Published: 6 June 2012

\section{References}

1. Brenner BM, Rector F: Brenner and Rector's The Kidney. Philidelphia: Saunders; 82008.

2. Zeisberg M, Kalluri R: Reversal of experimental renal fibrosis by BMP7 provides insights into novel therapeutic strategies for chronic kidney disease. Pediatr Nephrol 2008, 23(9):1395-1398.

3. Kalluri R, Weinberg RA: The basics of epithelial-mesenchymal transition. J Clin Invest 2009, 119(6):1420-1428.

4. Bedi S, Vidyasagar A, Djamali A: Epithelial-to-mesenchymal transition and chronic allograft tubulointerstitial fibrosis. Transplant Rev (Orlando) 2008, 22(1):1-5.

5. Savagner P: Leaving the neighborhood: molecular mechanisms involved during epithelial-mesenchymal transition. Bioessays 2001, 23(10):912-923.

6. Thiery JP: Epithelial-mesenchymal transitions in development and pathologies. Curr Opin Cell Biol 2003, 15(6):740-746.

7. Moustakas A, Heldin CH: Signaling networks guiding epithelialmesenchymal transitions during embryogenesis and cancer progression. Cancer Sci 2007, 98(10):1512-1520.

8. Zeisberg M, Maeshima Y, Mosterman B, Kalluri R: Renal fibrosis. Extracellular matrix microenvironment regulates migratory behavior of activated tubular epithelial cells. Am J Pathol 2002, 160(6):2001-2008.

9. Yang J, Liu Y: Dissection of key events in tubular epithelial to myofibroblast transition and its implications in renal interstitial fibrosis. Am J Pathol 2001, 159(4):1465-1475.

10. Turley EA, Veiseh M, Radisky DC, Bissell MJ: Mechanisms of disease: epithelial-mesenchymal transition-does cellular plasticity fuel neoplastic progression? Nat Clin Pract Oncol 2008, 5(5):280-290.

11. Gal A, Sjoblom T, Fedorova L, Imreh S, Beug H, Moustakas A: Sustained TGF beta exposure suppresses Smad and non-Smad signalling in mammary epithelial cells, leading to EMT and inhibition of growth arrest and apoptosis. Oncogene 2008, 27(9):1218-1230.

12. Tse JC, Kalluri R: Mechanisms of metastasis: epithelial-to-mesenchymal transition and contribution of tumor microenvironment. J Cell Biochem 2007, 101(4):816-829

13. Ozdamar $B$, Bose R, Barrios-Rodiles $M$, Wang HR, Zhang $Y$, Wrana JL: Regulation of the polarity protein Par6 by TGFbeta receptors controls epithelial cell plasticity. Science 2005, 307(5715):1603-1609.

14. Massague J: TGFbeta in Cancer. Cell 2008, 134(2):215-230.

15. Massague J, Gomis RR: The logic of TGFbeta signaling. FEBS Lett 2006, 580(12):2811-2820.

16. Jayaraman $L$, Massague J: Distinct oligomeric states of SMAD proteins in the transforming growth factor-beta pathway. J Biol Chem 2000, 275(52):40710-40717.

17. Chacko BM, Qin BY, Tiwari A, Shi G, Lam S, Hayward LJ, De Caestecker M, Lin K: Structural basis of heteromeric smad protein assembly in TGF-beta signaling. Mol Cell 2004, 15(5):813-823.

18. Inman GJ, Nicolas FJ, Callahan JF, Harling JD, Gaster LM, Reith AD, Laping NJ, Hill CS: SB-431542 is a potent and specific inhibitor of transforming growth factor-beta superfamily type I activin receptor-like kinase (ALK) receptors ALK4, ALK5, and ALK7. Mol Pharmacol 2002, 62(1):65-74.

19. Halder SK, Beauchamp RD, Datta PK: A specific inhibitor of TGF-beta receptor kinase, SB-431542, as a potent antitumor agent for human cancers. Neoplasia 2005, 7(5):509-521.

20. Piek E, Moustakas A, Kurisaki A, Heldin CH, ten Dijke P: TGF-(beta) type I receptor/ALK-5 and Smad proteins mediate epithelial to mesenchymal transdifferentiation in NMuMG breast epithelial cells. J Cell Sci 1999, 112(Pt 24):4557-4568.

21. Lan HY, Mu W, Tomita N, Huang XR, Li JH, Zhu HJ, Morishita R, Johnson RJ: Inhibition of renal fibrosis by gene transfer of inducible Smad7 using ultrasound-microbubble system in rat UUO model. J Am Soc Nephrol 2003, 14(6):1535-1548.

22. Zavadil J, Cermak L, Soto-Nieves N, Bottinger EP: Integration of TGF-beta/ Smad and Jagged1/Notch signalling in epithelial-to-mesenchymal transition. Embo J 2004, 23(5):1155-1165. 
23. Kalluri R, Neilson EG: Epithelial-mesenchymal transition and its implications for fibrosis. J Clin Invest 2003, 112(12):1776-1784.

24. Zeisberg M, Kalluri R: The role of epithelial-to-mesenchymal transition in renal fibrosis. J Mol Med 2004, 82(3):175-181.

25. Derynck R, Zhang YE: Smad-dependent and Smad-independent pathways in TGF-beta family signalling. Nature 2003, 425(6958):577-584.

26. Massague J, Seoane J, Wotton D: Smad transcription factors. Genes Dev 2005, 19(23):2783-2810.

27. Boden SD, Zdeblick TA, Sandhu HS, Heim SE: The use of rhBMP-2 in interbody fusion cages. Definitive evidence of osteoinduction in humans: a preliminary report. Spine (Phila Pa 1976) 2000, 25(3):376-381.

28. Zeisberg M, Hanai J, Sugimoto H, Mammoto T, Charytan D, Strutz F, Kalluri R: BMP-7 counteracts TGF-beta1-induced epithelial-tomesenchymal transition and reverses chronic renal injury. Nat Med 2003, 9(7):964-968.

29. Itoh S, Thorikay M, Kowanetz M, Moustakas A, Itoh F, Heldin CH, ten Dijke P. Elucidation of Smad requirement in transforming growth factor-beta type I receptor-induced responses. J Biol Chem 2003, 278(6):3751-3761

30. Yang J, Dai C, Liu Y: A Novel Mechanism by which Hepatocyte Growth Factor Blocks Tubular Epithelial to Mesenchymal Transition. J Am Soc Nephrol 2005, 16(1):68-78

31. Yang J, Dai C, Liu Y: Hepatocyte growth factor suppresses renal interstitial myofibroblast activation and intercepts Smad signal transduction. Am J Pathol 2003, 163(2):621-632.

32. Mizuno S, Nakamura T: Suppressions of chronic glomerular injuries and TGF-beta 1 production by HGF in attenuation of murine diabetic nephropathy. Am J Physiol Renal Physiol 2004, 286(1):F134-143.

33. Yang J, Liu Y: Delayed administration of hepatocyte growth factor reduces renal fibrosis in obstructive nephropathy. Am J Physiol Renal Physiol 2003, 284(2):F349-357.

34. Janda E, Lehmann K, Killisch I, Jechlinger M, Herzig M, Downward J, Beug H, Grunert S: Ras and TGF[beta] cooperatively regulate epithelial cell plasticity and metastasis: dissection of Ras signaling pathways. J Cell Biol 2002, 156(2):299-313

35. Xie L, Law BK, Chytil AM, Brown KA, Aakre ME, Moses HL: Activation of the Erk pathway is required for TGF-beta1-induced EMT in vitro. Neoplasia 2004, 6(5):603-610

36. Bakin AV, Rinehart C, Tomlinson AK, Arteaga CL: p38 mitogen-activated protein kinase is required for TGFbeta-mediated fibroblastic transdifferentiation and cell migration. J Cell Sci 2002, 115(Pt 15):3193-3206.

37. Brown K, Bhowmick NA: Linking TGF-beta-mediated Cdc25A inhibition and cytoskeletal regulation through RhoA/p160(ROCK) signaling. Cell Cycle 2004, 3(4):408-410.

38. Valcourt U, Kowanetz M, Niimi $\mathrm{H}$, Heldin $\mathrm{CH}$, Moustakas A: TGF-beta and the Smad signaling pathway support transcriptomic reprogramming during epithelial-mesenchymal cell transition. Mol Biol Cell 2005, 16(4):1987-2002

39. Grande M, Franzen A, Karlsson JO, Ericson LE, Heldin NE, Nilsson M: Transforming growth factor-beta and epidermal growth factor synergistically stimulate epithelial to mesenchymal transition (EMT) through a MEK-dependent mechanism in primary cultured pig thyrocytes. J Cell Sci 2002, 115(Pt 22):4227-4236.

40. Das S, Becker BN, Hoffmann FM, Mertz JE: Complete reversal of epithelial to mesenchymal transition requires inhibition of both ZEB expression and the Rho pathway. BMC Cell Biol 2009, 10:94.

41. Eger A, Stockinger A, Park J, Langkopf E, Mikula M, Gotzmann J, Mikulits W, Beug $H$, Foisner R: beta-Catenin and TGFbeta signalling cooperate to maintain a mesenchymal phenotype after FosER-induced epithelial to mesenchymal transition. Oncogene 2004, 23(15):2672-2680.

42. Batlle E, Sancho E, Franci C, Dominguez D, Monfar M, Baulida J, Garcia De Herreros A: The transcription factor snail is a repressor of E-cadherin gene expression in epithelial tumour cells. Nat Cell Biol 2000, 2(2):84-89.

43. Moreno-Bueno G, Cubillo E, Sarrio D, Peinado H, Rodriguez-Pinilla SM, Villa S, Bolos V, Jorda M, Fabra A, Portillo F, et al: Genetic profiling of epithelial cells expressing E-cadherin repressors reveals a distinct role for Snail, Slug, and E47 factors in epithelial-mesenchymal transition. Cancer Res 2006, 66(19):9543-9556.

44. Shirakihara T, Saitoh M, Miyazono K: Differential regulation of epithelial and mesenchymal markers by deltaEF1 proteins in epithelial mesenchymal transition induced by TGF-beta. Mol Biol Cell 2007, 18(9):3533-3544.

45. Aigner K, Descovich L, Mikula M, Sultan A, Dampier B, Bonne S, van Roy F, Mikulits W, Schreiber M, Brabletz T, et al: The transcription factor ZEB1 (deltaEF1) represses Plakophilin 3 during human cancer progression. FEBS Lett 2007, 581(8):1617-1624.

46. Eger A, Aigner K, Sonderegger S, Dampier B, Oehler S, Schreiber M, Berx G, Cano A, Beug H, Foisner R: DeltaEF1 is a transcriptional repressor of Ecadherin and regulates epithelial plasticity in breast cancer cells. Oncogene 2005, 24(14):2375-2385.

47. Peinado H, Olmeda D, Cano A: Snail, Zeb and bHLH factors in tumour progression: an alliance against the epithelial phenotype? Nat Rev Cancer 2007, 7(6):415-428.

48. Vandewalle C, Van Roy F, Berx G: The role of the ZEB family of transcription factors in development and disease. Cell Mol Life Sci 2009, 66(5):773-787.

49. Van de Putte T, Maruhashi M, Francis A, Nelles L, Kondoh H, Huylebroeck D, Higashi Y: Mice lacking ZFHX1B, the gene that codes for Smadinteracting protein-1, reveal a role for multiple neural crest cell defects in the etiology of Hirschsprung disease-mental retardation syndrome. Am J Hum Genet 2003, 72(2):465-470.

50. Ahn SM, Cha JY, Kim J, Kim D, Trang HT, Kim YM, Cho YH, Park D, Hong S: Smad3 regulates E-cadherin via miRNA-200 pathway. Oncogene 2011.

51. Xiong M, Jiang L, Zhou Y, Qiu W, Fang L, Tan R, Wen P, Yang J: MiR-200 family regulates TGF-\{beta\}1-induced renal tubular epithelial to mesenchymal transition through Smad pathway by targeting ZEB1 and ZEB2 expression. Am J Physiol Renal Physiol 2011.

52. Kong D, Banerjee S, Ahmad A, Li Y, Wang Z, Sethi S, Sarkar FH: Epithelial to mesenchymal transition is mechanistically linked with stem cell signatures in prostate cancer cells. PLoS One 2010, 5(8):e12445.

53. Liu Y, El-Naggar S, Darling DS, Higashi Y, Dean DC: Zeb1 links epithelialmesenchymal transition and cellular senescence. Development 2008 135(3):579-588.

54. Postigo AA, Dean DC: Differential expression and function of members of the zfh-1 family of zinc finger/homeodomain repressors. Proc Natl Acad Sci USA 2000, 97(12):6391-6396.

55. Korpal M, Lee ES, Hu G, Kang Y: The miR-200 family inhibits epithelialmesenchymal transition and cancer cell migration by direct targeting of E-cadherin transcriptional repressors ZEB1 and ZEB2. J Biol Chem 2008, 283(22):14910-14914

doi:10.1186/1755-1536-5-S1-S28

Cite this article as: Das et al:: Reversal of transforming growth factor- $\beta$ induced epithelial-to-mesenchymal transition and the ZEB proteins. Fibrogenesis \& Tissue Repair 2012 5(Suppl 1):S28.

\section{Submit your next manuscript to BioMed Central and take full advantage of:}

- Convenient online submission

- Thorough peer review

- No space constraints or color figure charges

- Immediate publication on acceptance

- Inclusion in PubMed, CAS, Scopus and Google Scholar

- Research which is freely available for redistribution

Submit your manuscript at www.biomedcentral.com/submit
C Biomed Central 